\title{
Effects of different treatment regimens of methylprednisolone on rat diaphragm contractility, immunohistochemistry and biochemistry
}

\author{
R.H.H. van Balkom*, H.F.M. van der Heijden*, H.T.B. van Moerkerk**, \\ J.H. Veerkamp**, J.A.M. Fransen+, L.A. Ginsel+, H.Th.M. Folgering*, \\ C.L.A. van Herwaarden*, P.N.R. Dekhuijzen*
}

Effects of different treatment regimens of methylprednisolone on rat diaphragm contractility, immunohistochemistry and biochemistry. R.H.H. van Balkom, H.F.M. van der Heijden, H.T.B. van Moerkerk, J.H. Veerkamp, J.A.M. Fransen, L.A. Ginsel, H.Th.M. Folgering, C.L.A. van Herwaarden, P.N.R. Dekhuijzen. (CERS Journals Ltd 1996.

ABSTRACT: Systemic corticosteroid therapy may affect diaphragm structure and function. We postulated that functional, immunohistochemical and biochemical characteristics of rat diaphragm were less affected by alternate-day methylprednisolone (MP) administration, and more by repeated bursts of MP, in comparison to daily s.c MP.

Sixty adult rats were randomized into four groups: saline s.c.; MP continuously (MP-C), $1 \mathrm{mg} \cdot \mathrm{kg}^{-1}$ daily, MP alternate-day therapy (MP-A), $2 \mathrm{mg} \cdot \mathrm{kg}^{-1}$ every other day; or MP in bursts (MP-B), MP $2 \mathrm{mg}^{-k^{-1}}$ daily for 2 weeks, saline for 4 weeks, MP $2 \mathrm{mg} \cdot \mathrm{kg}^{-1}$ daily for 2 weeks. The total treatment period was 8 weeks. Contractile properties of isolated diaphragm strips were measured. Antibodies reactive with type I, IIa, IIx and IIb myosin heavy chains were used for immunohistochemical analysis. Biochemical evaluation included markers of fast energy supply, glycogenolytic activity, $\beta$-oxidation capacity and oxidative capacity.

The force-frequency curve was depressed in all MP groups. Fibre type I, IIx and IIb cross-sectional area (CSA) decreased in all MP groups. Burst therapy decreased the contribution of type IIb fibres to total diaphragm muscle area. MP-A affected glycogenolytic activity less than MP-C. Burst MP therapy reduced creatine kinase (CK) activity and $\beta$-oxidation capacity compared to MP-C. Oxidative capacity was increased in all MP groups.

In conclusion, although the methylprednisolone treatment regimens affected diaphragm muscle morphology and bioenergetic enzyme activities in different ways, force generation decreased in all methylprednisolone treated groups to the same extent.

Eur Respir J., 1996, 9, 1217-1223.

Recently, animal and clinical studies have shown evidence of respiratory muscle dysfunction induced by treatment with corticosteroids [1,2]. Morphological changes, such as selective type IIb fibre atrophy, were observed in animal studies following administration of fluorinated steroids [3, 4]. Nonfluorinated steroids, however, caused loss of diaphragm function without muscle atrophy, suggesting myopathy [4].

The mechanisms by which nonfluorinated steroids cause myopathy are in part unknown. Changes in myosin heavy chain composition in the muscle fibres may contribute, since myosin heavy chain turnover rate in muscle cells was decreased following dexamethasone therapy [5]. These myosin heavy chains determine myosin adenosine triphosphatase (ATP-ase) activity and the speed of shortening in the muscle fibres and are, therefore, partly responsible for contractile properties. Polla et al. [6] reported a complete disappearance of rat diaphragm muscle fibres containing IIb myosin heavy chains (MyHCs) following cortisone acetate $100 \mathrm{mg} \cdot \mathrm{kg}^{-1} \cdot \mathrm{day}^{-1}$ for 11 days. It is not
Dept of *Pulmonary Diseases, **Biochemistry, and ${ }^{+}$Cell Biology and Histology, University of Nijmegen, The Netherlands.

Correspondence: RHH van Balkom

Dept of Pulmonary Diseases

University Hospital Nijmegen

PO Box 9109

6500 HB Nijmegen

The Netherlands

Keywords: Alternate-day therapy

animal

burst therapy

contractility

corticosteroids

immunohistochemistry

Received: July 71995

Accepted after revision January 291996

This study was supported by a grant from the Dutch Asthma Foundation. known whether similar changes occur after administration of lower, clinically more relevant dosages.

Changes in energy substrate and enzyme activities may also contribute to the onset of steroid-induced myopathy. A consistent observation is the increase in glycogen content in the diaphragm [7, 8]. However, conflicting effects on diaphragm mitochondrial function were found following corticosteroid therapy $[9,10]$. This may be explained by the differences in the dosage, duration, and types of steroids studied.

In addition, the severity of structural and biochemical changes in the respiratory muscles may depend on the treatment regimens applied. Alternate-day glucocorticoid therapy may reduce side-effects, since anti-inflammatory potency appears to persist longer than the undesirable metabolic effects $[11,12]$. The clinical efficacy of alternate-day therapy was similar in patients with chronic obstructive pulmonary disease (COPD) or stable asthma compared to daily treatment $[13,14]$. Another treatment regimen, short-term high-dose steroid therapy is often 
applied during exacerbations of COPD or asthma. Repeated episodes of high-dose steroid administration, in this study referred to as "bursts", may cause more severe sideeffects. This concept is supported by the observation that recovery from acute steroid myopathy, caused by shorttime high-dose steroid administration, appears to take several months [15]. Such a prolonged recovery period was also shown in a recent animal study [16].

We postulate that the structure and function of the rat diaphragm: 1) is less affected by alternate-day corticosteroid administration; and 2) is more affected by repeated bursts, in comparison to daily administration. In order to test this hypothesis, we studied functional, immunohistochemical and biochemical changes in rat diaphragm induced by continuous, alternate-day and burst administration of the nonfluorinated steroid, methylprednisolone.

\section{Methods}

\section{Study design, animals and treatment}

Sixty adult male outbred Wistar rats, aged 18-20 weeks, mean $( \pm \mathrm{SD})$ weight $525 \pm 35 \mathrm{~g}$, were randomized into four groups:

control (C), saline $0.2 \mathrm{~mL} \cdot$ day $^{-1}$ s.c.;

methylprednisolone (MP) continuously (MP-C), MP 1 $\mathrm{mg} \cdot \mathrm{kg}^{-1} \cdot \mathrm{day}^{-1}$ s.c.;

MP alternate-day therapy (MP-A), MP $2 \mathrm{mg} \cdot \mathrm{kg}^{-1}$ s.c. every other day alternating with saline $0.2 \mathrm{~mL}$ s.c.; MP in bursts (MP-B), MP $2 \mathrm{mg} \cdot \mathrm{kg}^{-1} \cdot \mathrm{day}^{-1}$ s.c. for 2 weeks followed by saline $0.2 \mathrm{~mL}$ s.c. for 4 weeks and by MP $2 \mathrm{mg} \cdot \mathrm{kg}^{-1} \cdot \mathrm{day}^{-1}$ s.c. for 2 weeks.

Each injection was of similar volume $(\sim 0.2 \mathrm{~mL})$. Over 8 weeks, the animals were injected s.c. daily between $8.30 \mathrm{~h}$ and $1000 \mathrm{~h}$ in the neck. The total dose of steroids administered was equal in all treatment groups. The rats were fed ad libitum, maintained on a 12/12 h light-dark regimen, and weighed twice weekly. At the end of the treatment period, contractile properties, immunohistochemical and biochemical characteristics of the diaphragm were examined. All animals were investigated between 23 and $30 \mathrm{~h}$ after the last injection. Adrenal and diaphragm weights were measured immediately following dissection. The study was approved by the local Animal Experiments Committee of the University of Nijmegen.

\section{Contractile properties}

The rats were anaesthetized with sodium pentobarbital (70 $\mathrm{mg} \cdot \mathrm{kg}^{-1}$ i.p.) and a polyethylene cannula was inserted through a tracheotomy. The animals were mechanically-ventilated with an oxygen-enriched gas mixture (airflow $0.5 \mathrm{~mL} \cdot \mathrm{g}^{-1}$ body weight $\cdot \mathrm{min}^{-1}$, respiratory frequency 70 breaths $\cdot \mathrm{min}^{-1}$, and a duty cycle $50 \%$ ). The diaphragm was quickly removed through a combined laparotomy and thoracotomy and was immediately immersed in a cooled, oxygenated Krebs solution at a $\mathrm{pH}$ of 7.4. This solution consisted of $\left(\mathrm{mmol} \cdot \mathrm{L}^{-1}\right): 137 \mathrm{NaCl}, 4 \mathrm{KCl}, 2$
$\mathrm{MgCl}_{2}, 1 \mathrm{KH}_{2} \mathrm{PO}_{4}, 24 \mathrm{NaHCO}_{3}, 2.7 \mathrm{CaCl}_{2}$, and 7 glucose. D-tubocurarine chloride $25 \mu \mathrm{M}$ (Sigma Chemicals, The Netherlands) was added to prevent spontaneous neuromuscular activity.

Two small rectangular bundles, parallel to the long axis of the muscle fibres, were dissected from the middle part of the lateral costal region of each hemidiaphragm. Silk sutures were firmly tied to both ends of the bundle to serve as anchoring points. Each bundle was placed in a tissue bath between two large platinum stimulating electrodes. The tissue baths were filled with Krebs solution at $37^{\circ} \mathrm{C}$ and were oxygenated with $95 \% \mathrm{O}_{2}$ and $5 \%$ $\mathrm{CO}_{2}$. The central tendon insertion of the bundles was tied to a fixed point and the costal margin origin to an isometric force transducer (Sensotec, model 31/1437; Columbus, OH, USA). Data acquisition and storage were performed using a Dash-16 interface and Twist-Trigger software (I.D.-electronics, University of Nijmegen, The Netherlands). Stimulations were applied with a Grass S 48 stimulator (Quincy, MA, USA). Maximal twitch force was reached at $34 \mathrm{~V}$. To ensure supramaximal stimulation, subsequent stimulations were performed with a $20 \%$ higher voltage $(40 \mathrm{~V})$. The pulse duration was set on 0.2 ms. Twitch stimuli were used to determine the optimal length (Lo), followed by a 15 min thermoequilibration period [17]. The following measurements were made.

Twitch characteristics. Two twitches were recorded at Lo to obtain maximal twitch tension $(P \mathrm{t})$, contraction time $(\mathrm{CT})$, and half relaxation time $(1 / 2 \mathrm{RT})$. The averages were used for further analysis.

Maximal tetanic contraction. Two maximal tetanic stimuli (with a frequency of $160 \mathrm{~Hz}$ and a train duration of $250 \mathrm{~ms}$ ) were generated to obtain maximal tetanic tension $\left(P_{\mathrm{o}}\right)$.

Force-frequency $(F F)$ protocol. Muscle bundles were stimulated every 2 min with the following order of frequencies: $25,160,50,160,80,160,120$ and $160 \mathrm{~Hz}$ (train duration $250 \mathrm{~ms}$ ). Forces were also expressed as percentage of the average force at $160 \mathrm{~Hz}$ before and after each stimulus [4, 18].

The generated force was expressed per cross-sectional area $\left(\mathrm{kg} \cdot \mathrm{cm}^{-2}\right)$. Cross-sectional area (CSA) was measured by dividing diaphragm bundle weight by muscle density $\left(1.056 \mathrm{mg} \cdot \mathrm{mm}^{-3}\right)$ and bundle length.

\section{Immunohistochemical procedures}

Muscle strips obtained from the costal part of the right hemidiaphragm were embedded in Tissue-Tek ${ }^{\circledR}$ in a plastic holder. The muscle fibres were oriented parallel to the long side of the holder. Subsequently, these specimens were quickly frozen in isopentane cooled in liquid $\mathrm{N}_{2}$, followed by further freezing in liquid $\mathrm{N}_{2}$. Serial crosssections were cut at $7 \mu \mathrm{m}$ with a cryostat kept at $-30^{\circ} \mathrm{C}$. Antimyosin heavy chain antibodies (Regeneron Pharmaceuticals, New York, USA) were used for morphometric examination. The following antibodies were used: BAD5 reactive with type I MyHCs; SC-71 reactive with type IIa MyHCs; BF-35 reactive with type I, IIa and IIb but not with type IIx MyHCs; and BF-F3 reactive with 
type IIb MyHCs [19]. Incubation with antimyosin heavy chain antibodies was performed at room temperature for $1 \mathrm{~h}$. Antibodies were subsequently labelled with ultra small immunogold reagent followed by silver enhancement (Aurion, Wageningen, The Netherlands). A minimum of 300 fibres was analysed from each diaphragm using a Sprynt-based, PC-Image digital analysis system (Bos B.V., Waddinxveen, The Netherlands).

\section{Biochemistry}

Parameters of the bioenergetic capacity of the diaphragm included the activities of creatine kinase (CK), responsible for the fast energy supply, the glycogenolytic enzyme phosphorylase, and the mitochondrial enzymes 3-hydroxyacyl-CoA dehydrogenase (HADH), a marker for the $\beta$-oxidation capacity, and citrate synthase (CS), an index of citric acid cycle activity.

Fat and tendon were quickly removed from remains of the left and right hemidiaphragm. Subsequently, these diaphragm parts were frozen in liquid $\mathrm{N}_{2}$ and stored at $-80^{\circ} \mathrm{C}$. Segments of freshly frozen diaphragm were thawed in ice-cooled buffer containing $250 \mathrm{mM}$ sucrose, $2 \mathrm{mM}$ ethylenediamine tetra-acetic acid (EDTA) and 10 $\mathrm{mM}$ Tris- $\mathrm{HCl}$ ( $\mathrm{pH} 7.4)$. In this buffer, muscle homogenates $\left(5 \% \mathrm{wt} \cdot \mathrm{vol}^{-1}\right)$ were prepared by hand homogenization, using a Potter-Elvehjem glass-teflon homogenizer.

CK activity was determined with the Boehringer CKNAC activated kit [20], and expressed in mmol reduced nicotinamide adenine dinucleotide phosphate (NADPH) formed $\cdot \mathrm{min}^{-1} \cdot \mathrm{g}$ tissue. Total phosphorylase $(\mathrm{a}+\mathrm{b})$ activity was assayed according to the method described by JACOBS and co-workers [20]. Phosphorylase activity was expressed as $\mu \mathrm{mol}$ NADPH formed $\cdot \mathrm{min}^{-1} \cdot \mathrm{g}$ tissue. $\mathrm{HADH}$ activity was assessed at $50 \mu \mathrm{M}$ acetoacyl-CoA [22] and expressed in nmol HADH oxidized. $\mathrm{min}^{-1} \cdot \mathrm{g}$ tissue. CS activity was determined at $25^{\circ} \mathrm{C}$ [23], and was expressed as $\mu \mathrm{mol}$ coenzyme A $(\mathrm{CoA})$ formed $\cdot \mathrm{min}^{-1} \cdot \mathrm{g}$ tissue. All other above-mentioned measurements were performed at $37^{\circ} \mathrm{C}$. The assays for metabolic enzymes were performed spectrophotometrically in duplicate. The coefficient of variation for the assays applied was $\sim 5 \%$.

\section{Data analysis}

Data of contractile properties of the two bundles obtained from one rat were averaged. The Statistical Package for the Social Sciences (SPSS)/PC+ package V5.0.1 (Chicago, Ill, USA) was used for statistical analysis. Data were compared using one-way analysis of variance (ANOVA) followed by Duncan's multiple-range test. Repeated measures ANOVA was used for growth curve analysis, and a two-way ANOVA was used to detect treatment differences in force generation during the FF protocol. Results were considered significant at p-values less than 0.05 . Data are expressed as mean $\pm \mathrm{SD}$.

\section{Results}

\section{Body, muscle and adrenal weight}

Figure 1 shows the body weight curve during the 8 week treatment period. A significant effect of steroid

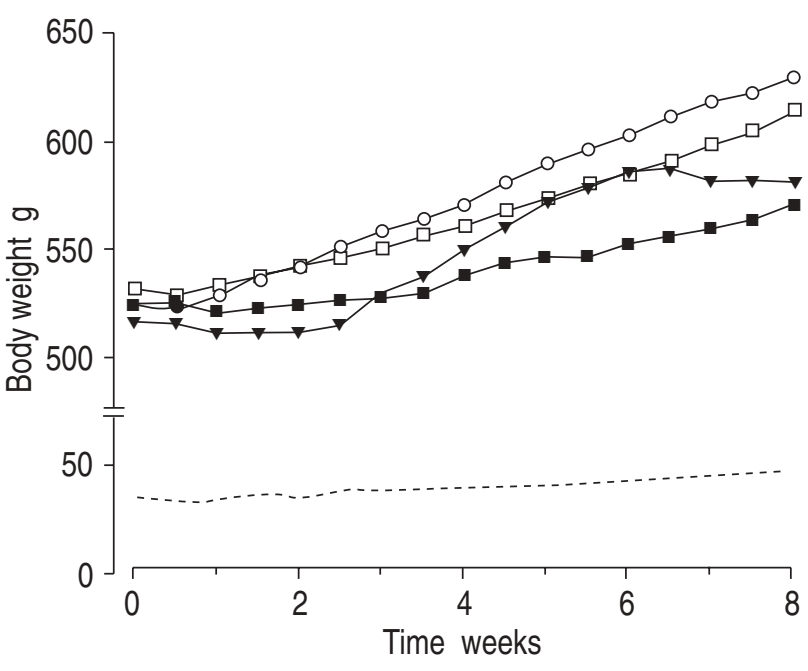

Fig. 1. - Mean growth curve for the four groups. - O- : control; $\longrightarrow$ : MP-C; - - : MP-A; —— : MP-B; ------: pooled standard deviation $(\mathrm{p}=0.039)$. MP: methylprednisolone; MP-C: MP continuously, $1 \mathrm{mg} \cdot \mathrm{kg}^{-1}$ daily; MP-A: MP alternate day therapy, $2 \mathrm{mg} \cdot \mathrm{kg}^{-1}$ every other day; MP-B: MP in bursts, $2 \mathrm{mg} \cdot \mathrm{kg}^{-1}$ daily for 2 weeks, saline for 4 weeks, MP $2 \mathrm{mg} \cdot \mathrm{kg}^{-1}$ for 2 weeks.

treatment on growth curve was noted throughout this period $(\mathrm{p}=0.039)$. Continuous MP administration affected body growth most. Body weights of the MP-A animals closely tracked those of the control group. Administration in bursts temporarily inhibited growth.

No differences in absolute diaphragm weights were observed. Diaphragm weight, normalized for body weight, was also similar in all groups (Control $0.0132 \pm 0.001 \%$; MP-C $0.0143 \pm 0.001 \%$; MP-A $0.0136 \pm 0.001 \%$; MP-B $0.0141 \pm 0.002 \%)$. Absolute adrenal weight was reduced in all MP treatment groups. Adrenal weights in the treatment groups were reduced in proportion to body weight (Control 0.0082 $\pm 0.0014 \%$; MP-C 0.0077 $\pm 0.0008 \%$; MPA $0.0074 \pm 0.0007 \%$; MP-B $0.0079 \pm 0.001 \%$ ).

\section{Contractile properties}

Diaphragm bundle dimensions did not differ between the four groups (average length $\sim 16.5 \mathrm{~mm}$, thickness $\sim 0.67$ $\mathrm{mm}$, width $\sim 1.8 \mathrm{~mm}$, and weight $\sim 26 \mathrm{mg}$ ). $P$ t and $P_{\mathrm{o}}$, normalized for CSA, decreased by $7.0-9.5 \%$ in all MP groups $(\mathrm{p}=0.07)$. Twitch characteristics did not differ between the groups (table 1).

The FF curves, expressed as absolute values, showed significant differences in force generation $(p=0.026)$ in all groups treated with MP. Force generation was equally reduced in all MP groups (fig. 2). MP treatment affected force generation at all stimulation frequencies in a similar way. The percentage decrease in force production of the final $160 \mathrm{~Hz}$ stimulation during the FF protocol was similar in the three MP groups, and did not differ from control (MP-C 11.4 $\pm 10.0 \%$; MP-A $11.7 \pm 7.5 \%$; MP-

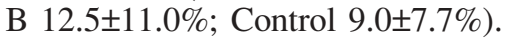

\section{Immunohistochemistry}

Methylprednisolone administrated in bursts (MP-B) caused a shift in fibre distribution from type IIb to type IIx in comparison to control $(\mathrm{p}<0.05)$ (table 2). 
Table 1. - Diaphragm contractile properties

\begin{tabular}{lccccc}
\hline Treatment & $\begin{array}{c}P \mathrm{t} \\
\mathrm{kg} \cdot \mathrm{cm}^{-2}\end{array}$ & $\begin{array}{c}\mathrm{CT} \\
\mathrm{ms}\end{array}$ & $\begin{array}{c}1 / 2 \mathrm{RT} \\
\mathrm{ms}\end{array}$ & $\begin{array}{c}P_{\mathrm{o}} \\
\mathrm{kg} \cdot \mathrm{cm}^{-2}\end{array}$ & $P \mathrm{t} / P_{\mathrm{o}}$ \\
\hline Control & $0.64(0.18)$ & $29.3(1.8)$ & $17.7(1.3)$ & $2.23(0.51)$ & $0.29(0.03)$ \\
MP-C & $0.58(0.20)$ & $28.8(2.1)$ & $17.9(1)$ & $2.02(0.65)$ & $0.29(0.02)$ \\
MP-A & $0.60(0.15)$ & $29.2(2.3)$ & $18.1(1.1)$ & $2.07(0.42)$ & $0.29(0.03)$ \\
MP-B & $0.59(0.23)$ & $29.2(2.6)$ & $18.1(1.6)$ & $2.02(0.74)$ & $0.29(0.04)$ \\
\hline
\end{tabular}

Pt: twitch tension; CT: contraction time; 1/2RT: half relaxation time; Po: maximal tetanic tension; MP: methylprednisolone; MP-C: MP continuously, $1 \mathrm{mg} \cdot \mathrm{kg}^{-1}$ daily; MP-A: MP alternate-day therapy, $2 \mathrm{mg} \cdot \mathrm{kg}^{-1}$ every other day; MP-B: MP in bursts, $2 \mathrm{mg} \cdot \mathrm{kg}^{-1}$ daily for 2 weeks, saline for 4 weeks, MP $2 \mathrm{mg} \cdot \mathrm{kg}^{-1}$ for 2 weeks.

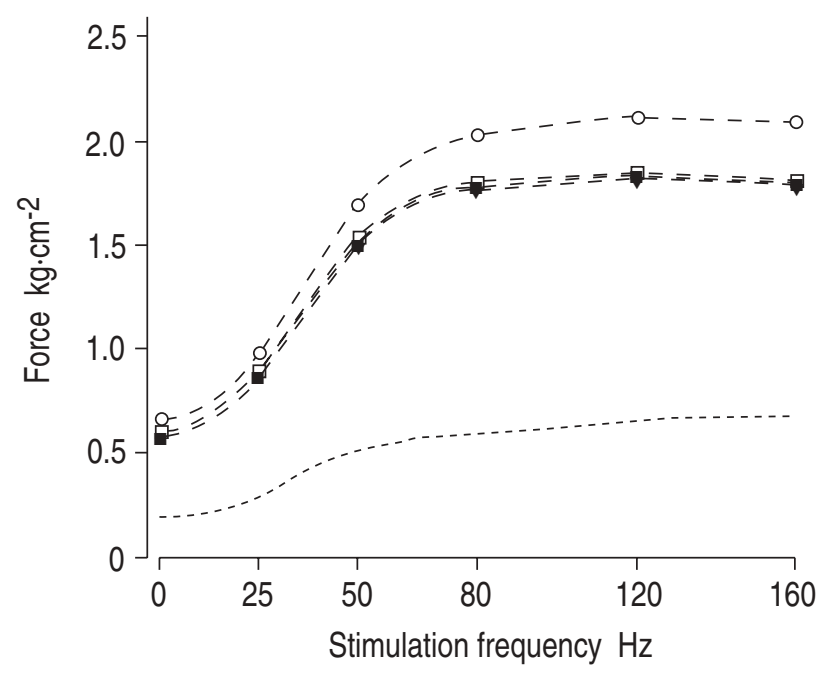

Fig. 2. - Force-frequency curve. -.-O- : control; …- : MP-C; : MP-A; :- : MP-B; ----- : pooled standard deviation. For abbreviations see legend to figure 1 .

Significant atrophy of type I, IIx and IIb fibres was observed in all MP groups (fig. 3). The differences in type IIa fibre CSA, as shown in figure 3, were significant but very small. The degree of type IIx atrophy was less following alternate-day in comparison to continuous MP therapy. In addition, type IIx CSA decreased in the MP-B group compared to MP-C. Thus, type IIx fibre atrophy was most pronounced following bursts and least affected by alternate-day steroid therapy compared to daily treatment (fig. 3). In contrast, the degree of type IIb fibre atrophy was greater in the MPA animals compared to MP-C.

As a result of the decrease in number of type IIb fibres in the MP-B group, the relative contribution of type IIb fibres to the total muscle area of the diaphragm was decreased compared to control (fig. 4).

Table 2. - Fibre type distribution

\begin{tabular}{lcccc}
\hline Treatment & $\begin{array}{c}\text { Type I } \\
\%\end{array}$ & $\begin{array}{c}\text { Type IIa } \\
\%\end{array}$ & $\begin{array}{c}\text { Type IIx } \\
\%\end{array}$ & $\begin{array}{c}\text { Type IIb } \\
\%\end{array}$ \\
\hline Control & $32.7(4.1)$ & $33.5(4.2)$ & $28.3(4.1)$ & $5.5(4.3)$ \\
MP-C & $33.4(3.6)$ & $31.6(6.1)$ & $31.4(4.2)$ & $3.7(3.7)$ \\
MP-A & $34.6(3.5)$ & $33.4(3.9)$ & $28.7(3.5)$ & $3.3(3.6)$ \\
MP-B & $33.6(3.1)$ & $31.5(3.5)$ & $33.2(4.9)^{\#}$ & $1.8(2.0)^{*}$
\end{tabular}

*: $\mathrm{p}<0.05$, compared to control; \#: $\mathrm{p}<0.05$, compared to control and the MP-A group. For abbreviations see legend to table 1.

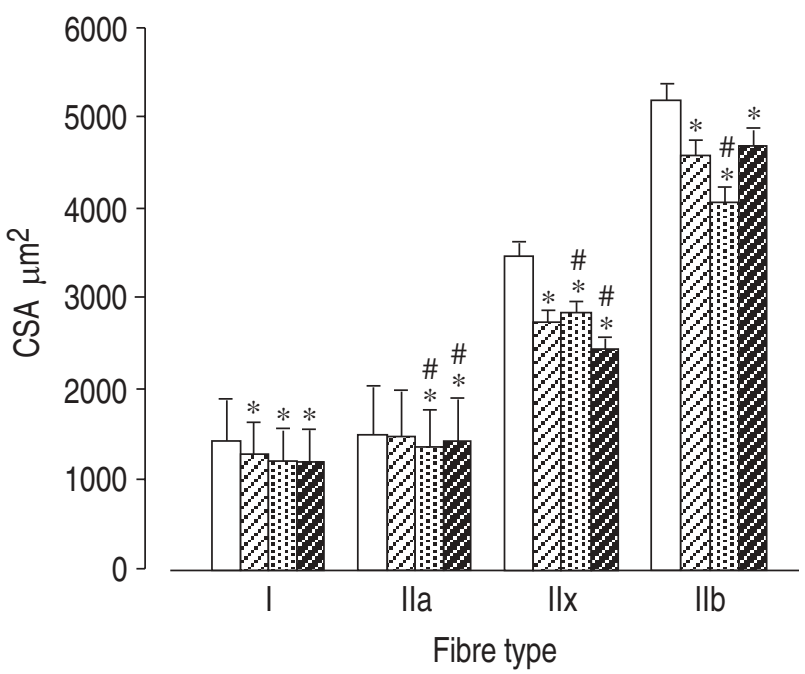

Fig. 3. - Fibre type cross-sectional area (CSA). $\square$ : control; $\square$ : MP-C; $\square$ : MP-A; $\square$ : MP-B. *: $\mathrm{p}<0.05$, compared to control; \#: $\mathrm{p}<0.05$, compared to MP-C. For abbreviations see legend to figure 1 .

\section{Biochemistry}

The data on bioenergetic enzyme activities are shown in table 3. An approximately $30 \%$ increase in CS activity was found in all MP treatment groups, indicating an increased oxidative capacity $(\mathrm{p}<0.01)$.

Treatment with the three MP regimens affected energy supply by different mechanisms. Firstly, continuous steroid

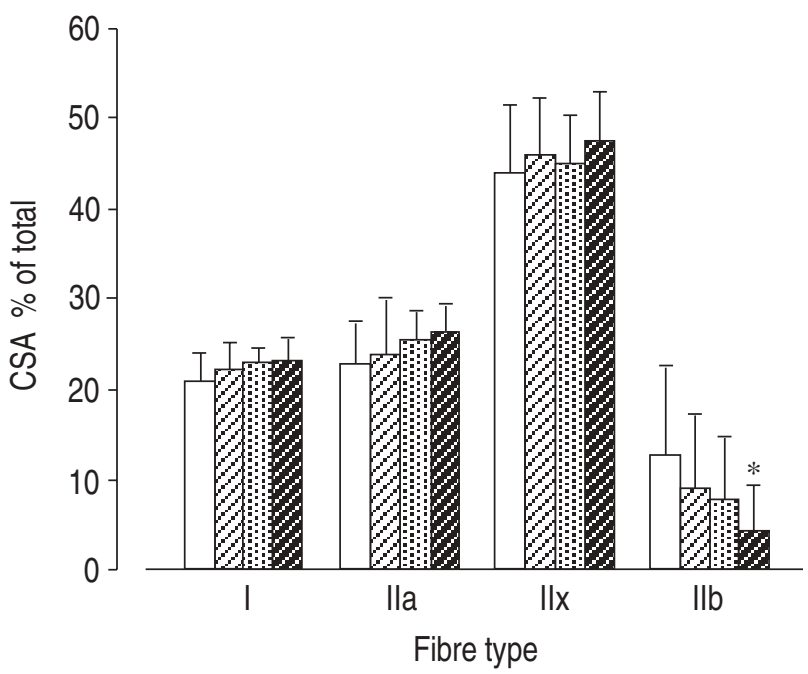

Fig. 4. - Relative fibre type contribution to the total muscle area of the diaphragm. $\square$ : control; $\square$ : MP-C; $\square$ : MP-A; $\square$ : MP-B. * $\mathrm{p}<0.05$, compared to control. For abbreviations see legend to figure 1 . 
Table 3. - Biochemical analysis of the diaphragm

\begin{tabular}{lcccc}
\hline Treatment & \multicolumn{1}{c}{$\begin{array}{c}\mathrm{CK} \\
\mathrm{kU} \cdot \mathrm{g}^{-1}\end{array}$} & $\begin{array}{c}\text { Phosphorylase } \\
\mathrm{U} \cdot \mathrm{g}^{-1}\end{array}$ & $\begin{array}{c}\mathrm{HADH} \\
\mathrm{U} \cdot \mathrm{g}^{-1}\end{array}$ & $\begin{array}{c}\mathrm{CS} \\
\mathrm{U} \cdot \mathrm{g}^{-1}\end{array}$ \\
\hline Control & $2.18(0.54)$ & $35.5(3.3)$ & $2.86(0.44)$ & $23.9(2.3)$ \\
MP-C & $1.82(0.64)$ & $32.6(2.0)^{\#}$ & $2.83(0.66)$ & $30.8(6.5)^{*}$ \\
MP-A & $1.48(0.32)^{*}$ & $38.0(3.2)$ & $2.84(0.51)$ & $31.2(4.0)^{*}$ \\
MP-B & $1.39(0.47)^{*} \ddagger$ & $37.2(4.0)$ & $2.24(0.35)^{\#}$ & $30.6(4.8)^{*}$ \\
\hline
\end{tabular}

CK: creatine kinase; HADH: 3-hydroxyacyl-CoA dehydrogenase; CS: citrate synthase. For further abbreviations see legend to table $1 . *$ : $\mathrm{p}<0.01$, compared to control; $\$: \mathrm{p}<0.05$, compared to MP-C; \#: $\mathrm{p}<0.01$, compared to all other groups.

administration decreased glycogenolytic activity, indicated by a decrease in phosphorylase activity. Secondly, glycogenolytic activity was less affected following alternate-day steroid administration in comparison to daily treatment. Finally, burst MP administration affected CK activity and $\beta$-oxidation capacity, as indicated by $\mathrm{HADH}$, more in comparison to MP-C. Total phosphorylase activity, however, was higher in the MP-B group than in the MP-C group.

\section{Discussion}

The question in the present study was whether there were differences in changes in rat diaphragm following different corticosteroid treatment regimens. The data showed that the MP treatment regimens affected body weight, diaphragm morphology and bioenergetic capacity in a different way. Force generation, however, decreased to a similar extent in all MP treatment regimens. This apparent discrepancy can be explained by the fact that the net result of these combined morphometric and biochemical changes was an equal reduction in force generation.

\section{Rationale of methylprednisolone dosage}

The rationale for the dose of MP used in the present study was based on an absorption of $60 \%$ after i.m. injection [18], and the finding that the s.c. route may require higher doses to produce effects similar to i.m. administration [24]. Similar anti-inflammatory potency and metabolism of methylprednisolone have been described in rats and humans $[25,26]$. Therefore, $1 \mathrm{mg} \cdot \mathrm{kg}^{-1}$ of MP, as administrated in the MP-C group, may be equivalent to a dose of $35 \mathrm{mg} \cdot \mathrm{day}^{-1}$ in a $60 \mathrm{~kg}$ human. A daily dose of $35 \mathrm{mg}$ methylprednisolone is not uncommon in the treatment of patients with COPD during an exacerbation [27].

The duration of biological effects of methylprednisolone in rat is difficult to analyse because of the nonlinear clearance [28]. In addition, no close correlation was found between the circulating half-life of a glucocorticoid and its duration of action [12]. However, the differences in growth curves observed in the present study indicate that there are differences in biological effects between continuous and alternate-day therapy.

\section{Contractile properties}

The reduction in diaphragm force generation following MP therapy, observed in this study during the FF protocol, cannot be explained by differences in oxygenation of the bundles, since their measures were similar in all groups. Since MP has little or no mineralocorticoid activity, an overestimation of the CSA due to an increase in extracellular fluid is unlikely. Glucocorticoids are known to cause protein wasting [29]. A reduction in myofibrillar protein density would result in a reduction in the number of cross-bridges available for interaction with actin. This can lead to a reduction in force generation. Other plausible causes for the impairment in diaphragm force are the morphological and biochemical changes.

In previous studies, no changes in twitch and maximal tetanic tension were found following $0.5 \mathrm{mg} \cdot \mathrm{kg}^{-1}$ daily MP for 6 weeks [17], or following $5 \mathrm{mg} \cdot \mathrm{kg}^{-1}$ daily prednisolone for 4 weeks [4]. In addition, cortisone acetate, $100 \mathrm{mg} \cdot \mathrm{kg}^{-1} \cdot \mathrm{day}^{-1}$ for 10 days, did not lead to functional changes in the diaphragm [18]. The downward shift of the FF curve in the present study may be explained by differences in effects of dosage and duration of the steroid therapy on morphological and biochemical characteristics (see below).

\section{Immunohistochemistry}

Immunohistochemical differentiation between type IIx and IIb fibres, as performed in this study, may be of importance since type IIx and IIb MyHCs possess biochemical and functional differences. Maximum velocity of shortening [30] and resistance to fatigue [31] in type IIx muscle fibres are intermediate between those of type IIa and IIb fibres. Twitch and tetanic tension are higher in IIb in comparison with IIa and IIx motor units [31]. Type IIx muscle fibres have a rich mitochondrial content, in contrast to type IIb fibres [19].

In support of our hypothesis, the degree of type IIx atrophy was less following alternate-day MP administration compared to continuous therapy. On the other hand, type IIb fibre atrophy was more pronounced in the alternate-day group. Cortisone acetate treatment in rabbits resulted in atrophy of all diaphragm fibre types [32], whereas no changes in fibre CSA were found in rats following prednisolone treatment [4]. Muscle fibre atrophy can be the result of steroid-induced protein wasting due to a reduction in protein synthesis and an increase in intracellular proteolysis [29]. However, muscle fibre atrophy may also occur as an attempt to increase oxygen delivery by decreasing the cell diameter, in this way creating a smaller diffusion distance [33].

Burst therapy reduced the number of type IIb fibres and decreased the contribution of type IIb fibres to total 
diaphragm muscle area. Cortisone acetate administration (100 $\mathrm{mg} \cdot \mathrm{kg}^{-1}$ daily for 11 days) actually resulted in a complete disappearance of fibres containing IIb MyHCs, while fibre type distribution was not described [6]. These changes were not detected using ATP-ase staining [4, 32].

The cause of the shift from type IIb to type IIx fibres following burst therapy is not entirely clear. This shift may be caused by a disappearance of type IIb fibres combined with an appearance of new type IIx fibres. The following observations, however, support the occurrence of a transformation from type IIb to IIx fibres. Corticosteroids decrease the rate of amino acid incorporation into the MyHCs, resulting in a decreased turnover rate of the MyHCs in the muscle cell. As this decrease in turnover rate is most pronounced in the fast twitch muscle fibres [5], type IIb fibres are likely to be affected most. This may lead to a decrease in IIb MyHCs in type IIb fibres. Since genes of IIx MyHCs are coexpressed in a number of type IIb muscle fibres [34], an increase of IIx MyHCs in type IIb muscle fibres may occur to compensate for the decrease in type IIb MyHCs. To our knowledge, there is no evidence that type IIb fibres disappear while new type IIx fibres are generated. The shift from type IIb to type IIx fibres following MP burst therapy is probably too small to cause functional changes at different stimulation frequencies.

\section{Biochemistry}

Treatment with MP resulted in a decrease in energy supply, as indicated by a reduction in CK activity or in glycogenolytic activity. This impairment in energy supply may have caused the increase in oxidative capacity in all MP groups. To what extent these differences in biochemistry were influenced by the fact that animals in the MP-A and MP-B group received $2 \mathrm{mg} \cdot \mathrm{kg}^{-1} \mathrm{MP} 23$ to $30 \mathrm{~h}$ before investigation, whereas, animals in the MP$\mathrm{C}$ group only received $1 \mathrm{mg} \cdot \mathrm{kg}^{-1}$, is not clear.

Creatine kinase rapidly rephosphorylates adenosine diphosphate (ADP) from phosphocreatine in order to keep a constant adenosine triphosphate (ATP) level in the muscle. A decrease in CK activity may, therefore, lead directly to a reduction in fast energy supply. CK activity decreased following steroid administration in bursts compared to MP-C. In patients with bronchial asthma, CK activity in the deltoid muscle decreased following prednisone treatment $\left(17 \mathrm{mg} \cdot \mathrm{day}^{-1}\right.$ for $\left.15 \mathrm{yrs}\right)$ [8].

The increase in glycogen storage in the diaphragm muscle following steroid administration found by FERGUSON et al. [35] may be the result of a decrease in glycogen breakdown, or an increase in glycogen production [7], or both [8]. Our data show that alternate-day and burst therapy did not affect glycogenolytic capacity, measured by phosphorylase activity, in contrast to continuous steroid administration.

Since the diaphragm muscle possesses a high $\beta$-oxidation capacity [36], it is unclear whether the $20 \%$ reduction in HADH activity, observed following steroid administration in bursts, has functional consequences. Short-term (10 days) prednisolone treatment $\left(5 \mathrm{mg} \cdot \mathrm{kg}^{-1}\right.$ daily s.c.) did not change HADH activity in rat diaphragm [9]. However, a decrease in HADH activity in vastus lateralis muscle of patients with rheumatoid arthritis occurred with low doses of prednisolone [37].
In the present study, administration of methylprednisolone resulted in an increase in oxidative capacity, as indicated by the increased CS activity, independent of the treatment regimen applied. This is in line with the increase in oxidative staining reaction in skeletal muscle reported by others [10]. Mitochondrial changes in rabbit diaphragm, following glucocorticoid administration, ranged from a numerical increase to the presence of enlarged and degenerated mitochondria [38]. In contrast to these observations, CS activity in rat diaphragm was reduced following $5 \mathrm{mg} \cdot \mathrm{kg}^{-1}$ prednisolone daily for 10 days. However, no changes in CS activity were reported following $0.5,1$ or $2 \mathrm{mg} \cdot \mathrm{kg}^{-1}$ daily [9], suggesting that enzyme activity was affected more using high dosages of prednisolone in comparison to low dosages. Reactions of metabolism to corticosteroids may also depend on the fibre type composition of the muscle [9, 35], because the resistance of different fibre types is believed to depend on their ability to compensate the steroid-induced deficiency of the glycogenolytic route by converting to oxidative metabolism [10].

In conclusion, force generation decreased in all methylprednisolone treated groups to an equal extent, although the methylprednisolone treatment regimens affected diaphragm muscle morphology and bioenergetic enzyme activities in a different way.

\section{References}

1. Dekhuijzen PNR, Decramer M. Steroid-induced myopathy and its significance to respiratory disease: a known disease rediscovered. Eur Respir J 1992; 5: 997-1003.

2. Decramer M, Lacquet LM, Fagard R, Rogiers P. Corticosteroids contribute to muscle weakness in chronic airflow obstruction. Am J Respir Crit Care Med 1994; 150: 11-16.

3. Wilcox PG, Hards JM, Bockhold K, Bressler B, Pardy RL. Pathologic changes and contractile properties of the diaphragm in corticosteroid myopathy in hamsters: comparison to peripheral muscle. Am J Respir Cell Mol Biol 1989; 1: 191-199.

4. Dekhuijzen PNR, Gayan-Ramirez G, de Bock V, Dom $\mathrm{R}$, Decramer M. Triamcinolone and prednisolone affect contractile properties and histopathology of rat diaphragm differently. J Clin Invest 1993; 92: 1534-1542.

5. Seene T. Turnover of skeletal muscle contractile proteins in the glucocorticoid myopathy. J Steroid Biochem 1994; 50: 1-4.

6. Polla B, Bottinelli R, Sandoli D, Sardi C, Reggiani C. Cortisone-induced changes in myosin heavy chain distribution in respiratory and hindlinb muscles. Acta Physiol Scand 1994; 151: 353-361.

7. Shoji S, Takagi A, Sugita H, Toyokura Y. Muscle glycogen metabolism in steroid-induced myopathy of rabbits. Exp Neurol 1974; 45: 1-7.

8. Fernandez-Sola J, Cusso R, Picado C, Vernet M, Grau JM, Urbano-Marquez A. Patients with chronic glucocorticoid treatment develop changes in muscle glycogen metabolism. J Neurol Sci 1993; 117: 103-106.

9. Lieu FK, Powers SK, Herb RA, et al. Exercise and glucocorticoid-induced diaphragmatic myopathy. J Appl Physiol 1993; 75: 763-771.

10. Vignos PJ, Greene R. Oxidative respiration of skeletal muscle in experimental corticosteroid myopathy. $J \mathrm{Lab}$ Clin Med 1973; 81: 365-378. 
11. Harter JG, Reddy WJ, Thorn GW. Studies on an intermittent corticosteroid dosage regimen. $N$ Engl J Med 1963; 269: 591.

12. Axelrod L. Glucocorticoid therapy. Med (Baltimore) 1976; 55: 39-65.

13. Blair GP, Light RW. Treatment of chronic obstructive pulmonary disease with corticosteroids: comparison of daily vs alternate-day therapy. Chest 1984; 86: 524-528.

14. Adinoff AD, Hollister JR. Steroid-induced fractures and bone loss in patients with asthma. N Engl J Med 1983; 309: 265-268.

15. Knox AJ, Mascie-Taylor BH, Muers MF. Acute hydrocortisone myopathy in acute severe asthma. Thorax 1986; 41: 411-412.

16. Dekhuijzen PNR, Gayan-Ramirez G, Bisschop A, de Bock V, Dom R, Decramer M. Recovery of corticosteroid-induced changes in contractile properties and morphology of rat diaphragm. Am J Respir Crit Care Med 1996; 153: 769-775.

17. Dekhuijzen PNR, Gayan-Ramirez G, Bisschop A, de Bock V, Dom R, Decramer M. Different effects of methylprednisolone and deflazacort on contractile properties and histopathology of rat diaphragm. Eur Respir J 1995; 8: 824-830.

18. Moore BJ, Miller MJ, Feldman HA, Reid MB. Diaphragm atrophy and weakness in cortisone-treated rats. J Appl Physiol 1989; 67: 2420-2426.

19. Schiaffino S, Gorza L, Sartore S, et al. Three myosin heavy chain isoforms in type 2 skeletal muscle fibers. $J$ Musc Res Cell Motility 1989; 10: 197-205.

20. Jacobs AEM, Oosterhof A, Veerkamp JH. Palmitate oxidation and some enzymes of energy metabolism in human muscle and cultured muscle cells. Int J Biochem 1987; 19: 1049-1054.

21. Jacobs AEM, Benders AAGM, Oosterhof A, Veerkamp $\mathrm{JH}$. Effects of growth medium, electrical stimulation and paralysis on various enzyme activities in cultured rat muscle cells: comparison with rat muscles in vivo. Int J Biochem 1992; 24: 751-758.

22. Bass A, Brdicka D, Eyer P, Hofer S, Pette D. Metabolic differentiation of distinct muscle types at the level of enzymatic organization. Eur J Biochem 1969; 10: 198-206.

23. Shepherd D, Garland PD. Citrate synthase from rat liver. Methods Enzymol 1969; 13: 11-16.

24. Frenkel JK, Havenhill MA. The corticoid sensitivity of golden hamsters, rats and mice. Lab Invest 1963; 12: 1204-1220.

25. Jasani MK. Anti-inflammatory steroids: mode of action in rheumatoid arthritis and homograft reaction. In: Vane JR, Ferreira SH, eds. Anti-inflammatory drugs. Berlin, Springer-Verlag, 1979; pp. 598-660.

26. Sarett LH, Patchett AA, Steelman SL. The effects of structural alteration on the anti-inflammatory properties of hydrocortisone. Prog Drug Res 1963; 5: 11-153.

27. British Thoracic Society guidelines. Acute severe asthma in adults and children. Thorax 1993; 48: S12S17.

28. Kong A-N, Jusko WJ. Disposition of methylprednisolone and its sodium succinate prodrug in vivo and in perfused liver of rats: nonlinear and sequential first-pass elimination. J Pharmacol Sci 1991; 80(5): 409-415.

29. Ruff RL. Endocrine myopathies. In: Engel AG, Banker BQ, eds., Myology. McGraw-Hill Book Co., 1986; pp. 1871-1906.

30. Schiaffino S, Ausoni S, Gorza L, Saggin L, Gundersen $\mathrm{K}$, Lomo T. Myosin heavy chain isoforms and velocity of shortening of type 2 skeletal muscle fibers. Acta Physiol Scand 1988; 134: 575-576.

31. Larsson L, Edstrom L, Lindergren B, Gorza L, Schiaffino S. MHC composition and enzyme-histochemical and physiological properties of a novel fast-twitch motor unit type. Am J Physiol 1991; 261: C93-C101.

32. Ferguson GT, Irvin CG, Cherniack RM. Effects of corticosteroids on respiratory muscle histopathology. Am Rev Respir Dis 1990; 142: 1047-1052.

33. Sweeney HL. The importance of creatine kinase reaction: the concept of metabolic capacitance. Med Sci Sports Exerc 1994; 26(1): 30-36.

34. Denardi C, Ausoni S, Moretti P, et al. Type-IIx myosin heavy chain is coded by a muscle fiber type-specific and developmentally regulated gene. J Cell Biol 1993; 123 : 823-835.

35. Ferguson GT, Irvin CG, Cherniack RM. Effects of corticosteroids on diaphragm function and biochemistry in the rabbit. Am Rev Respir Dis 1990; 141: 156-163.

36. Veerkamp JH, van Moerkerk HTB. Peroxisomal fatty acid oxidation in rat and human tissues: effect of nutritional state, clofibrate treatment and postnatal development in the rat. Biochim Biophys Acta 1986; 875: 301-310.

37. Danneskiold Samsoe B, Grimby G. The influence of prednisone on the muscle morphology and muscle enzymes in patients with rheumatoid arthritis. Clin Sci 1986; 71 : 693-701.

38. Afifi AK, Bergman RA. Steroid myopathy: a study of the evolution of the muscle lesion in rabbits. Johns Hopkins Med J 1969; 124: 66-86. 